\title{
STRUCTURAL OPTIMIZATION OF MACPHERSON CONTROL ARM UNDER FATIGUE LOADING
}

\author{
Javad Marzbanrad, Abolfazl Hoseinpour
}

Preliminary communication

In this research, the topology and shape optimization of a MacPherson control arm has been accomplished to achieve lighter weight. Present automotive market demands low cost and light weight component to meet the need of fuel efficient and cost effective vehicle. This in turn gives the rise to more effective use of materials for automotive parts which can reduce the mass of vehicle. Since automotive components are under dynamic loads which cause fatigue damage, considering fatigue criteria seems to be essential in designing automotive components. At first, in order to create severe loading condition for control arm some rough roads are generated through power spectral density. Then, the most critical loading conditions are obtained through multi body dynamics analysis of a full vehicle model. Then, the topology optimization is performed based on fatigue life criterion using HyperMesh software, which resulted in $50 \%$ mass reduction. In the next step a CAD model is created using CATIA software and shape optimization is performed to achieve accurate dimensions with less mass.

Keywords: fatigue life; MacPherson control arm; shape optimization; topology optimization

\section{Konstrukcijska optimizacija MacPherson upravljačke poluge pod zamornim opterećenjem}

Prethodno priopćenje

U ovom istraživanju izvršena je optimizacija topologije i oblika MacPherson upravljačke poluge u svrhu postizanja manje težina. Postojeće automobilsko tržište traži dijelove niske cijene i male težine, a za potrebe energetski učinkovitog, a jeftinog vozila. To zahtijeva učinkovitiju uporabu materijala za automobilske dijelove koji mogu dovesti do smanjene mase vozila. Budući da su automobilski dijelovi izloženi dinamičkim opterećenjima koja uzrokuju oštećenja zbog zamora, uzimanje u obzir kriterija zamora čini se bitnim u dizajniranju automobilskih dijelova. Kako bi se stvorili što teži uvjeti opterećenja upravljačke poluge, najprije su spektralnom gustoćom snage generirane neravne ceste. Zatim su, dinamičkom analizom karoserije kompletnog modela vozila, dobiveni najkritičniji uvjeti opterećenja. Nakon toga, izvršena je optimizacija topologije pomoću kriterija vijeka trajanja do zamora primjenom HyperMesh softvera, što je rezultiralo smanjenjem mase od $50 \%$. U sljedećem koraku kreiran je CAD model primjenom CATIA softvera i provedena optimizacija oblika kako bi se dobile točne dimenzije s manje mase.

Ključne riječi: MacPherson upravljačka poluga; optimizacija oblika; optimizacija topologije; vijek trajanja do zamora

\section{Introduction}

Considering the pollution is originated from automotive, one of the solutions for reducing produced fumes by cars and factories could be mass reduction. This approach leads to less energy and fossil fuel consumption. Different optimization methods help engineers and designers produce automotive components with low mass and high performance. In this article, optimization process of a MacPherson control arm under fatigue load is investigated. In the automotive suspension, an automobile's control arm or wishbone (A-arm or A-frame) is a nearly flat and roughly triangular suspension member (or sub-frame), that pivots in two places. The base of the triangle attaches at the frame and pivots on a bushing. The narrow end attaches to the steering knuckle and pivots on a ball joint. Two such devices per wheel make up a double wishbone suspension, while one control arm per wheel makes up a part, usually the lower part, of a MacPherson strut suspension or of various other configurations. Topology optimization is a mathematical technique that produces an optimized shape and material distribution for a structure within a given package space. The topology optimization technique yields a new design and optimal material distribution. Topology optimization allows designers to start with a design that already has the advantage of optimal material distribution and is ready for design fine tuning with shape or size optimization. Performing topology optimizations early in the conceptual design stage results in the generation of a good baseline design and contributes to a shorter design cycle.
Chiandussi et al. [4] have investigated the three dimensional topology optimization of a McPherson rear suspension sub-frame. The optimization method is based on maximization of total potential energy (compliance minimization), with imposing volume constraint as design constraint. The homogenization method is used during optimization process. Relative change in design domain volume has been considered as the convergence criterion. Song and Jung [19] presented an optimization of ADI upper control arm, based on FEM analysis, using both response surface method and Kriging model. They have revealed that although these methods are not the global optimal solution, the RSM and Kriging model leads to very closed optimal solution. Zhao et al. [23] presented structural optimization of stamped lower control arm by combining multi-body dynamic and traditional optimization technique. Doundkar [6] illustrated how topology optimization with fatigue criterion can be used in the design of engine mounting arm. These topology optimizations have fatigue life as design constraint and objective is volume minimization. Wan Muhamad et al. [20] investigated shape optimization of rear spindle component under fatigue loads using HyperWorks software.

\section{Methodology}

HyperWorksOptiStruct topology optimization with Fatigue Process Manager (FPM) is powerful tool to achieve lighter and more reliable conceptions. The fatigue life calculation involves accumulation of load versus time 
history data on the torture track and rough road by using accelerometer, material details to generate S-N curve and process details. Optimization process methodology used in this paper is shown in Fig. 1.

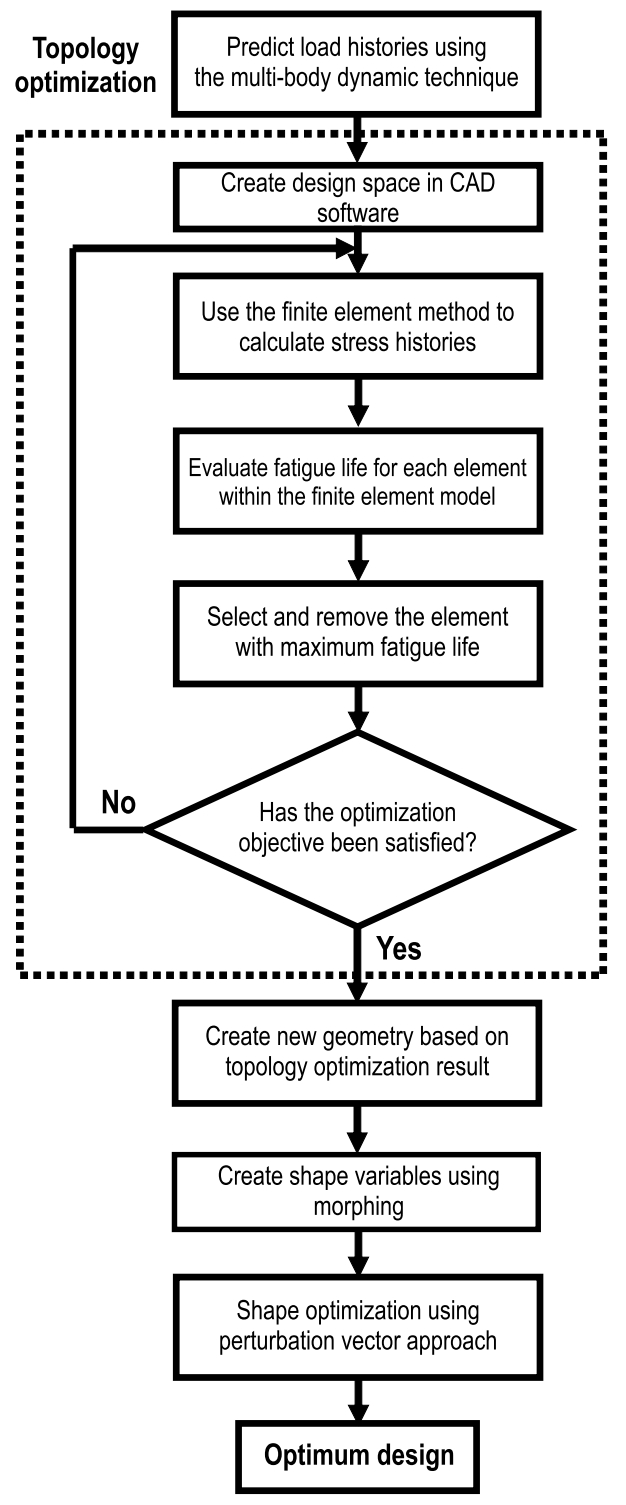

Figure 1 Flowchart of the optimization process

OptiStruct solves the following structural optimization problem as the following instruction:

$\min f(x)=f\left(x_{1}, x_{2}, \ldots, x_{n}\right)$

Subject to:

$$
\begin{aligned}
& g_{i}(x) \leq 0 ; j=1, \ldots, m \\
& x_{i}^{L} \leq x_{i} \leq x_{i}^{U} ; i=1, \ldots, n .
\end{aligned}
$$

The objective function $f(x)$ and the functions $g(x)$ in the constraint function are structural responses obtained from a finite element analysis. A constraint is considered active if it is satisfied exactly $(g=0)$; it is considered inactive if $g<0$; it is considered violated if $g>0$.

The selection of the vector of design variables $\mathrm{x}$ depends on the type of optimization being performed. In the topology optimization, the design variables are element densities. In the size optimization, the design variables are properties of structural elements. In the shape optimization, the design variables are the factors in a linear combination of the shape perturbations.

OptiStruct solves the topological optimization problems using the density method, also known as the SIMP method in the research community [11]. Under the topology optimization, the material density of each element should take a value of either 0 or 1 , defining the element as being either void or solid, respectively. Unfortunately, the optimization of a large number of discrete variables is computationally prohibitive. Therefore, representation of the material distribution problem in terms of continuous variables has to be used.

With the density method, the material density of each element is directly used as the design variable, and varies continuously between 0 and 1; these represent the state of void and solid, respectively. Intermediate values of density represent fictitious material. The stiffness of the material is assumed to be linearly dependent on the density. This material formulation is consistent with our understanding of common materials. For example, steel, which is denser than aluminium, is stronger than aluminium. Following this logic, the representation of fictitious material at intermediate densities does reflect engineering intuitions.

In general, the optimal solution of problems involves large grey areas of intermediate densities in the structural domain. Such solutions are not meaningful when we are looking for the topology of a given material, and not meaningful when considering the use of different materials within the design space. Therefore, some techniques need to be introduced to penalize intermediate densities and to force the final design to be represented by densities of 0 or 1 for each element. In this paper, the penalization technique used is the power law representation of elasticity properties $[9,11]$ which can be expressed for any solid 3-D or 2-D element as follows:

$\boldsymbol{K}^{\prime}(\rho)=\rho^{p} \boldsymbol{K}$

where $\boldsymbol{K}^{\prime}$ and $\boldsymbol{K}$ represent the penalized and the real stiffness matrix of an element, respectively, $\rho$ is the density and $p$ the penalization factor which is always greater than 1 .

By separating the domain into a finite element mesh, OptiStruct calculates material properties for each element. The OptiStruct algorithm alters the material distribution to optimize the user-defined objective under given constraints. Convergence occurs in line with the description provided on the Iterative solution page.

OptiStruct has the capability of performing shape optimization. In the shape optimization, the outer boundary of the structure is modified to solve the optimization problem [15]. Using finite element models, the shape is defined by the grid point locations. Hence, shape modifications change those locations. In the finite elements, the shape of a structure is defined by the vector of nodal coordinates $(x)$. In order to avoid mesh distortions due to the shape changes, changes of the shape of the structural boundary must be translated into changes of the interior of the mesh. 
The two most commonly used approaches to account for mesh changes during a shape optimization area) the basis vector approach and b) the perturbation vector approach. Both approaches refer to the definition of the structural shape as a linear combination of vectors.

In this study, the perturbation vector approach is utilized in which the structural shape change is defined as a linear combination of perturbation vectors. The perturbation vectors define changes of nodal locations with respect to the original finite element mesh with the following relations:

$$
x=x_{0}+\sum D V_{i} \cdot \boldsymbol{P} \boldsymbol{V}_{i}
$$

where $x$ is the vector of nodal coordinates, $x_{0}$ is the vector of nodal coordinates of the initial design, $\boldsymbol{P} \boldsymbol{V}_{i}$ is the perturbation vector associated to the design variable $D V_{i}$.

One challenge with post-processing topology optimization results is that the results may have several intermediate density elements or checkerboard patterns which can be either interpreted as solid members or as a void. Even if these semi-dense elements are interpreted as solid members, it makes it harder to manufacture such members.

OptiStruct offers the minimum member size control method which provides some control over member size in final topology designs by defining the least dimension required in the final design. It helps achieve a discrete solution by eliminating the intermediate density elements and checkerboard density pattern, resulting in a discrete and better-reinforced structure, which is easier to interpret and also easier to manufacture.

\section{Data acquisition}

\subsection{Road profile}

Since static loading condition could not represent severe condition for automotive component under the loads varying with time, especially front control arm, in this study dynamic analysis of front control arm is performed. At first, using the procedure explained in the previous research in the field of random time series with a specified spectral density function by Hullender [10], the rough road surfaces are generated. According to his results, it is possible to generate a random sequence of numbers which already has the desired frequency characteristics.

The first step of generating a random time series of road surface elevations $u(t)$, with a specific power spectral density, is to generate the discrete Fourier transform $U\left(f_{\mathrm{k}}\right)$ of $u(\mathrm{t})$ based on the desired spectral density function. By taking inverse discrete Fourier transform of $U\left(f_{\mathrm{k}}\right)$, the random sequence $u(t)$ is obtained. This can be done by generating random phase angles for each of the Fourier terms of $U\left(f_{\mathrm{k}}\right)$. The relationship between the road surface PSD and temporal frequency can be approximated as

$$
G_{\mathrm{u}}(f)=\frac{C_{\mathrm{sp}} \times\left(\frac{f}{V}\right)^{-N}}{V}
$$

where $G_{\mathrm{u}}(f)$ is the power spectral density of the elevation of road surface profile and $C_{\mathrm{sp}}$ and $N$ are constants as stated in Tab. 1 [21].

The discrete Fourier transform, $U\left(f_{\mathrm{k}}\right)$ is a complex number

$U\left(f_{\mathrm{k}}\right)=R\left(f_{\mathrm{k}}\right)+j \cdot I\left(f_{\mathrm{k}}\right)$

where $f_{\mathrm{k}}\left(f_{\mathrm{k}}=\frac{k}{N \cdot H}\right)$ is temporal frequency, $k=0,1$, $2, \ldots,(\mathrm{N}-1) ; N$ is the number of points to be generated to make up the random series and $H$ is the time interval between the points. $R\left(f_{\mathrm{k}}\right)$ and $I\left(f_{\mathrm{k}}\right)$ are real and imaginary parts of $U\left(f_{\mathrm{k}}\right)$, respectively.

Table 1 Values of constants parameters, $C_{\text {sp }}$ and $N$, for different types of road surfaces

\begin{tabular}{|c|l|c|c|c|}
\hline & \multicolumn{1}{|c|}{ Road Profile } & $N$ & $C_{\mathrm{sp}}$ & Type \\
\hline 1 & Smooth Runway & 3,8 & $4,3 \times 10^{-11}$ & $\mathrm{~A}$ \\
\hline 2 & Smooth Highway & 2,1 & $4,8 \times 10^{-7}$ & $\mathrm{~B}$ \\
\hline 3 & $\begin{array}{l}\text { Ride and Handling } \\
\text { TrackCan-Can }\end{array}$ & 1,8 & $2,27 \times 10^{-6}$ & $\mathrm{C}$ \\
\hline 4 & Highway with gravel & 2,1 & $4,4 \times 10^{-6}$ & $\mathrm{D}$ \\
\hline 5 & Rough Runway & 2,1 & $8,1 \times 10^{-6}$ & $\mathrm{D}$ \\
\hline 6 & Fatigue TrackCan-Can & 2,9 & $3,42 \times 10^{-5}$ & $\mathrm{E}$ \\
\hline 7 & Pasture & 1,6 & $3 \times 10^{-4}$ & $\mathrm{~F}$ \\
\hline 8 & Plowed Field & 1,6 & $6,5 \times 10^{-4}$ & $\mathrm{G}$ \\
\hline
\end{tabular}

Since during optimization, it is supposed that the most severe loading condition would be created for suspension control arm, the frequency range of generated road needs to include the natural frequency of suspension system. Since the natural frequency of unsprung mass is usually between 6 to $30 \mathrm{~Hz}$, the generated road covers the range of 0 to $50 \mathrm{~Hz}$. Using Eq. (5), the time interval $(H)$ is calculated as follows:

$$
f_{\max }=\frac{1}{2 H} \quad\left(f_{\max }=50 \mathrm{~Hz}\right)
$$

Hence, $H=0,01$

Discrete Fourier transform is used in the algorithm for generating random time series with specific spectral density, it is necessary that $N$ is equal to $2^{n}$, where $n$ is a positive integer.

On the other hand, standard cornering analysis in Adams/Car lasts $10 \mathrm{~s}$. So, in order to compare two main manoeuvres in dynamic analysis, cornering to strait driving effects, the total time of simulation should be considered about $10 \mathrm{~s}$. Based on these two conditions, N should be considered 1024 and then, total time of simulation is calculated as follows:

\section{Total time of simulation $=N \times H=10,24 \mathrm{~s}$}

The real and imaginary parts of Eq. (4) showing two terms of discrete Fourier transform $U\left(f_{\mathrm{k}}\right)$, may be obtained as [21]:

$R\left(f_{\mathrm{k}}\right)=\left(\sqrt{G_{\mathrm{u}}\left(f_{\mathrm{k}}\right) \frac{N \cdot H}{2}}\right) \cdot \cos \theta$ 


$$
I\left(f_{\mathrm{k}}\right)=\left( \pm j \cdot \sqrt{G_{\mathrm{u}}\left(f_{\mathrm{k}}\right) \frac{N \cdot H}{2}}\right) \cdot \sin \theta
$$

By using the random values with uniform probability density between 0 to $2 \pi$, for angle $\theta$, a random road surface elevations $u\left(t_{\mathrm{k}}\right)$ is obtained from inverse discrete Fourier transform of $U\left(f_{\mathrm{k}}\right)$ [12]. Then by means of relation between the time and velocity of vehicle, road elevations, $u(x)$, can be obtained as illustrated in Fig. 2 .

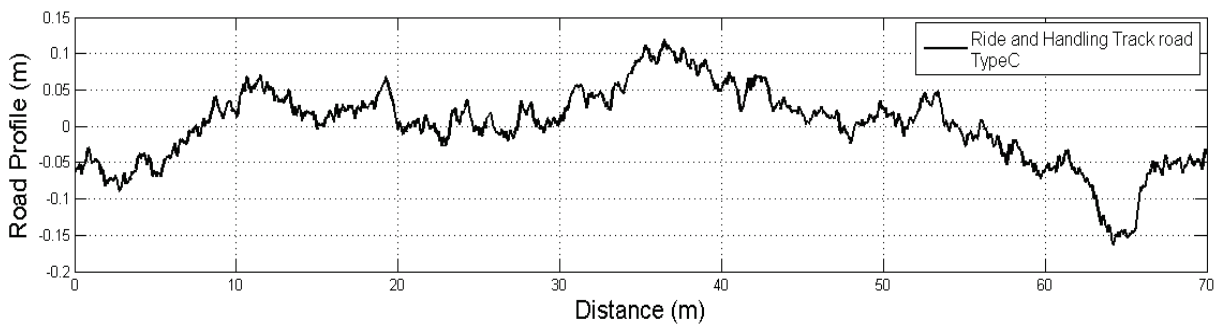

Figure 2 Road elevations versus length of the road

\subsection{Dynamic analysis}

For the next step, some ride and handling standard manoeuvres [7] are utilized to predict severe loading conditions on the MacPherson control arm. These manoeuvres consist of straight driving and cornering effects. For straight driving, four following manoeuvres are considered:

- $100 \mathrm{~km} / \mathrm{h}$ on road type B

- $\quad 75 \mathrm{~km} / \mathrm{h}$ on road type C

- $\quad 50 \mathrm{~km} / \mathrm{h}$ on road type D

- $25 \mathrm{~km} / \mathrm{h}$ on road type E.
For cornering effects, three following manoeuvres with constant radius $(30 \mathrm{~m})$ are considered:

- $\quad$ Slow cornering $(30 \mathrm{~km} / \mathrm{h}$ on road type C)

- Moderate cornering ( $40 \mathrm{~km} / \mathrm{h}$ on road type C)

- $\quad$ Fast cornering $(50 \mathrm{~km} / \mathrm{h}$ on road type C).

The corresponding force histories at the contact point between control arm and wheel knuckle (imposed forces to control arm) have been displayed to determine which manoeuvre creates the critical loading condition as shown in Fig. 3 and 4. As it can be observed from these figures, when the vehicle velocity increases, the applied forces to the control arm of suspension system will be enhanced.

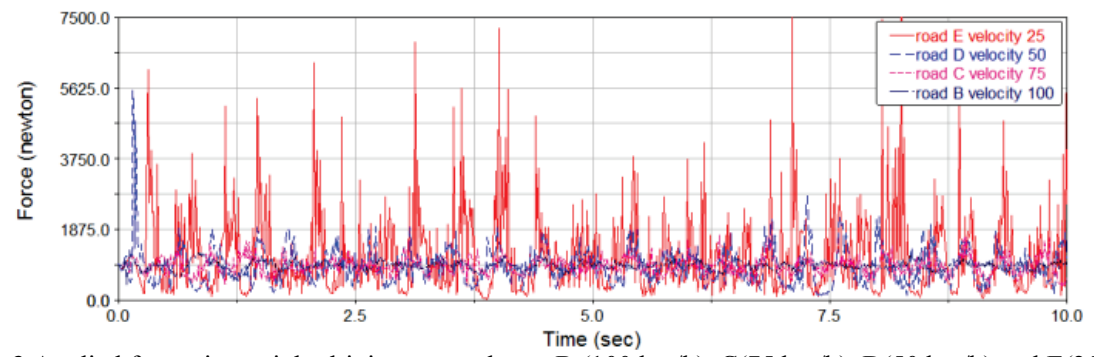

Figure 3 Applied forces in straight driving on road type B $(100 \mathrm{~km} / \mathrm{h}), \mathrm{C}(75 \mathrm{~km} / \mathrm{h}), \mathrm{D}(50 \mathrm{~km} / \mathrm{h})$ and E(25 km/h)

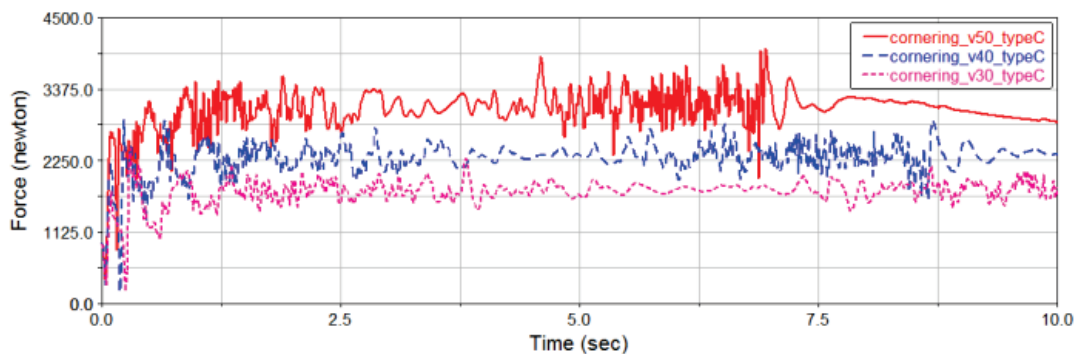

Figure 4 Applied forces in cornering effect on road type C with velocity 30,40 and $50 \mathrm{~km} / \mathrm{h}$

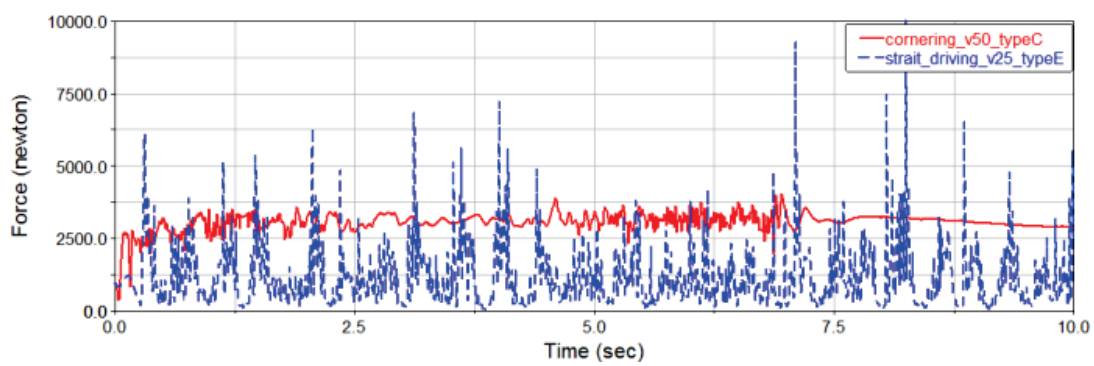

Figure 5 Force histories of straight driving on road type E and cornering on road type C 
Among these seven situations, two are more severe than the others as drawn in Fig. 5. Since these two force histories have different amplitudes and averages, fatigue analysis with damage criterion has been implemented for the sake of determining the most severe situation.

Cornering manoeuvre in road type $\mathrm{C}$ with constant velocity $50 \mathrm{~km} / \mathrm{h}$, of which the maximum fatigue damage is 331,6 , creates critical situation for MacPherson control arms shown in Fig. 6(a) and 6(b). Then, force history components obtained from cornering analysis have been used in this study for optimization process.
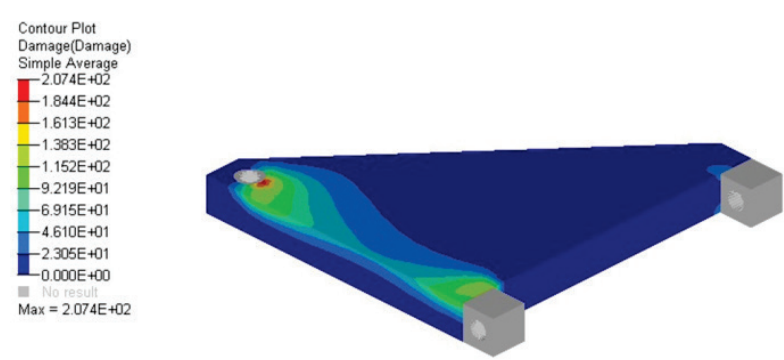

(a)
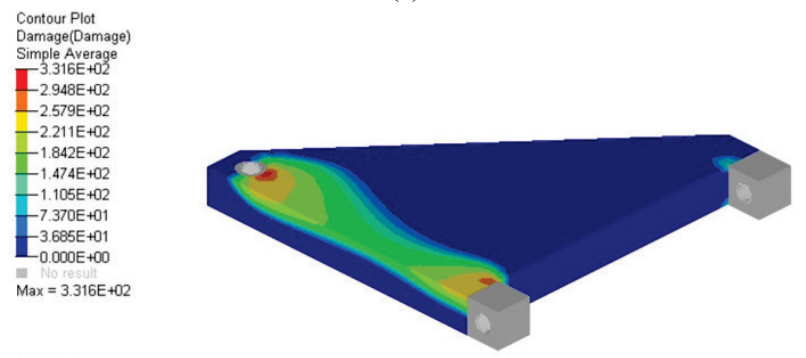

(b)

Figure 6 Distribution of fatigue damage for control arm under two manoeuvres; a) Strait Driving Effects b) Cornering Effects

\section{Optimization \\ 4.1 Modelling}

FE modelling of MacPherson control arm has been created by using HyperMesh as shown in Fig. 7. Control arm is constrained at two revolute joints located at $\mathrm{C}_{1}$ and $\mathrm{C}_{2}$ as shown in Tab. 2 and it is subjected to longitudinal and lateral forces at spherical joint located at B (see Fig. 7).

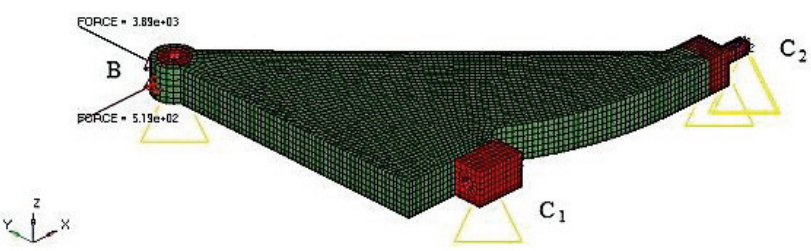

Figure 7 Loading and boundary condition of primary MacPherson control arm

Table 2 Boundary condition of MacPherson control arm

\begin{tabular}{|c|c|}
\hline Points & Movement constraints \\
\hline $\mathrm{C}_{1}$ & $\mathrm{U}_{2}, \mathrm{U}_{3}$ \\
\hline $\mathrm{C}_{2}$ & $\mathrm{U}_{1}, \mathrm{U}_{2}, \mathrm{U}_{3}$ \\
\hline $\mathrm{B}$ & $\mathrm{U}_{3}$ \\
\hline
\end{tabular}

The assigned material properties are given in Tab. 3 . S-N curve for Aluminium 7075-T6 is illustrated in Fig. 8; and two load time histories (see Fig. 9) in two appropriate directions (longitudinal and lateral) that are obtained from dynamic analysis are normalized (with respect to maximum load) to be applied as fatigue load-case.

\begin{tabular}{|c|c|c|c|c|c|}
\hline Properties & $\begin{array}{l}\text { Yield } \\
\text { Stress } \\
(\mathrm{MPa})\end{array}$ & $\begin{array}{c}\text { Ultimate } \\
\text { Tensile } \\
\text { Stress } \\
(\mathrm{MPa})\end{array}$ & $\begin{array}{l}\text { Density } \\
\left(\mathrm{kg} / \mathrm{m}^{3}\right)\end{array}$ & $\begin{array}{c}\text { Modulus } \\
\text { of } \\
\text { Elasticity } \\
(\mathrm{GPa})\end{array}$ & $\begin{array}{l}\text { Poisson } \\
\text { 's Ratio }\end{array}$ \\
\hline A7075-T6 & 450 & 530 & 2800 & $70 \mathrm{e} 3$ & 0,33 \\
\hline
\end{tabular}

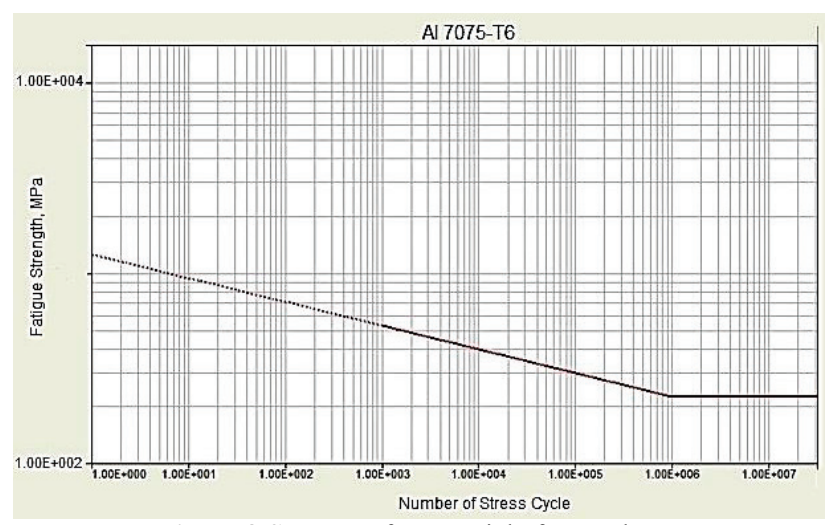

Figure $8 S-N$ curve for material of control arm

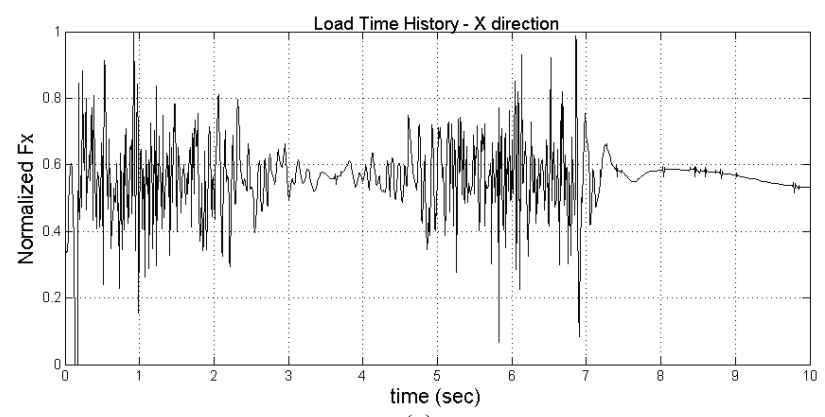

(a)

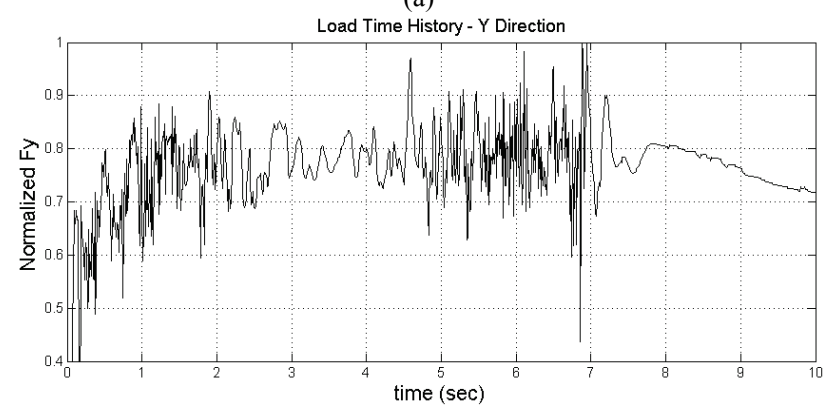

(b)

Figure 9 Normalized applied load on control arm a) longitudinal b) lateral

\subsection{Topology optimization}

In order to reduce the mass of control arm, the element density is the design variable, fatigue life is design constraint and compliance is considered as objective function which is supposed to be minimized. Based on the actual fatigue test and academic research (American society for testing and materials [1]), the lower bound of fatigue life is 1,3 million cycles.

On the other hand, considering manufacture process of stamped control arm, one constraint is used during definition of design and none design area in HyperMesh. By defining this constraint, unnecessary elements would 
be eliminated so that the arm could be manufactured via casting.

The elements which are violated from design constraint are eliminated during some acceptable iteration. The optimization process will stop when the compliance reduction is less than $1 \%$ comparing to previous iteration as illustrated in Fig. 10. Optimized topology is represented in Fig. 11 from two views.

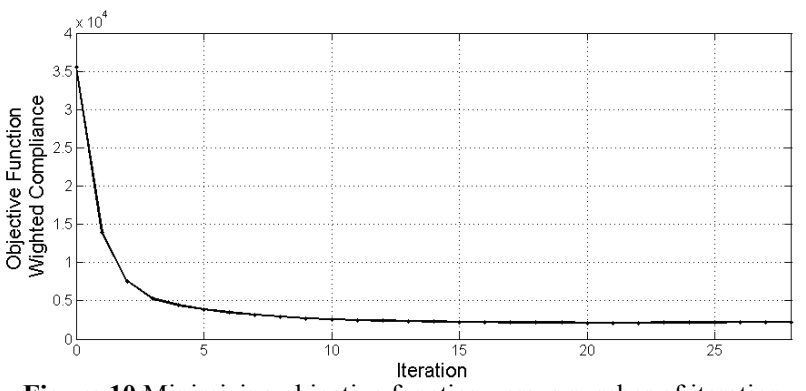

Figure 10 Minimizing objective function versus number of iteration

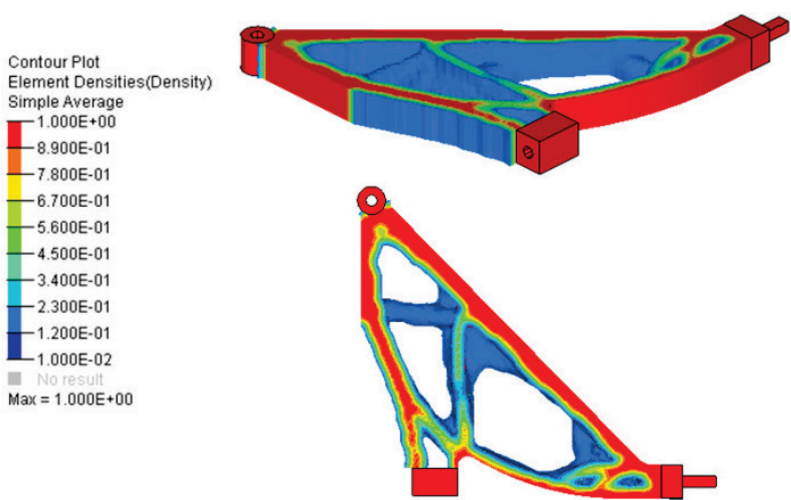

Figure 11 Optimized topology of MacPherson control arm isometric and top view

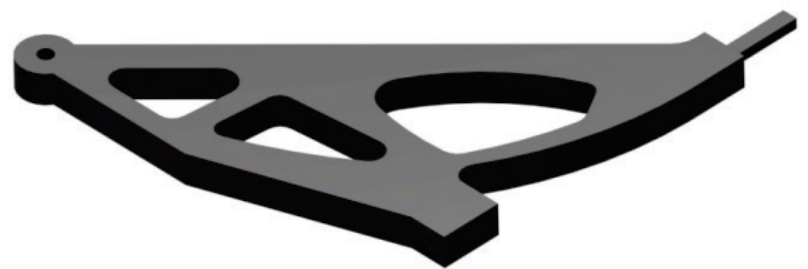

Figure 12 Modified optimized topology

Then, the model is modified (in CATIA software) to eliminate sharp edges to have a smooth model as represented in Fig. 12. By means of topology optimization and then modifying obtained topology, $38 \%$ reduction in the primary mass of the component is achieved. This model satisfies the constraints of maximum Von Mises stress and the fatigue life so that maximum Von Mises stress is $70,8 \mathrm{MPa}$ (below the yield stress limit) and minimum fatigue life is 1,46 million cycles (upper than the fatigue life constraint).There are significant gaps between the maximum Von Mises stress and the minimum fatigue life and those of design upper and lower bound respectively as in the topology optimization it is supposed to achieve just an optimal topology not necessarily optimum design. Stress and fatigue life distribution can be determined to be sure the optimal topology of control arm would be in the permissible limit as shown in Fig. 13. In order to achieve accurate dimensions and optimum design, shape optimization also needs to be followed.

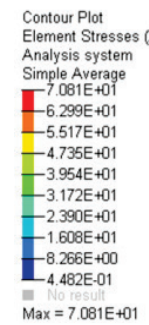

\begin{tabular}{|c|}
\hline $\begin{array}{l}\text { Contour Plot } \\
\text { Life(Life) } \\
\text { Simple Average } \\
-1.000 E+20\end{array}$ \\
\hline$-8.889 E+19$ \\
\hline$-7.778 E+19$ \\
\hline$-6.667 \mathrm{E}+19$ \\
\hline$-5.556 \mathrm{E}+19$ \\
\hline$-4.444 \mathrm{E}+19$ \\
\hline$-3.333 E+19$ \\
\hline$-2.222 E+19$ \\
\hline $\begin{array}{l}-1.111 \mathrm{E}+19 \\
-1464 \mathrm{E}+10\end{array}$ \\
\hline -1.464E+10 \\
\hline
\end{tabular}

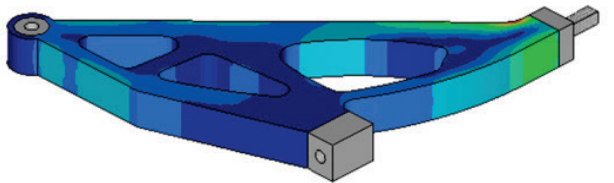

(a)

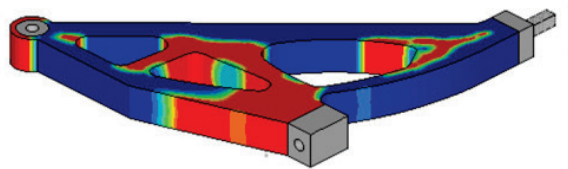

(b)
Figure 13 Design parameters distribution of control arm a) Stress b) fatigue life

\subsection{Shape Optimization}

In order to achieve optimal design with accurate dimensions, shape optimization of current model is required as illustrated in Fig. 14. Accordingly, the thickness and height of different links and radius of the arcs which are very important to reduce the stress concentration are considered as design variables. In the shape optimization, the fatigue life is considered as design constraint and the volume of design area is considered as objective function which is supposed to be minimized.

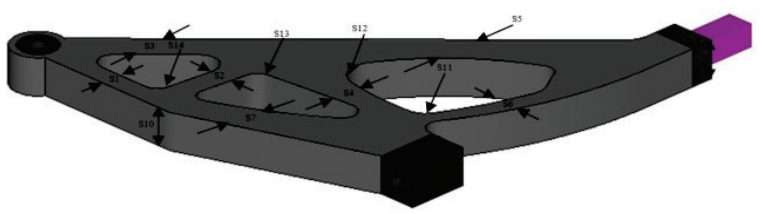

$t^{2}-x$

Figure 14 Shape variables

\section{$5 \quad$ Results}

In the shape optimization, 14 design variables are defined to achieve optimal solution as much as possible. Fig. 15 shows the change of design variables as compared to their possible amplitude at the last iteration in two adjacent columns. Amplitude of the shape changes have been defined so that the shape distortion during optimization would not occur. This was done via determination in HyperMorph module through trial and error.

The regions around the revolute joints are almost without significant change because of the manufacturing constraints and stress concentration, as it can be seen in Fig. 16. According to Fig. 15, since the design variables do not meet their upper bound, it can be derived that the final obtained shape is very close to the optimal design of the component. 
Finally, the optimal shape of MacPherson control arm with notation of fatigue life criterion is illustrated in Fig. 17. This model has the mass of 753 grams which shows mass reduction is $67 \%$ of the optimized topology and 80 $\%$ of the original mass. The result of stress and fatigue analysis is illustrated in Fig. 18 and Fig. 19 respectively.

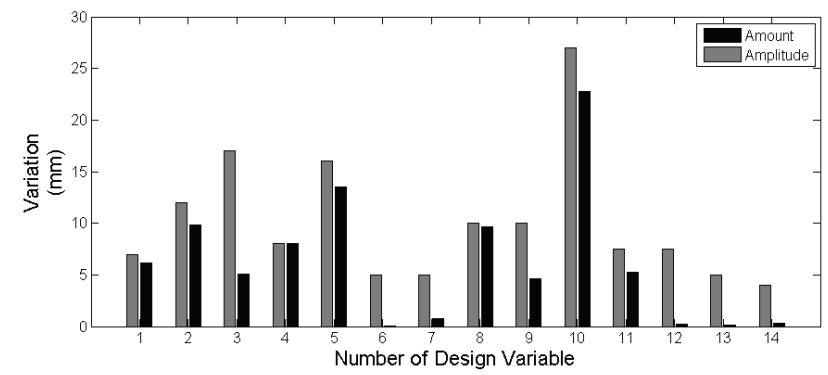

Figure 15 Changes of design variables and their amplitudes
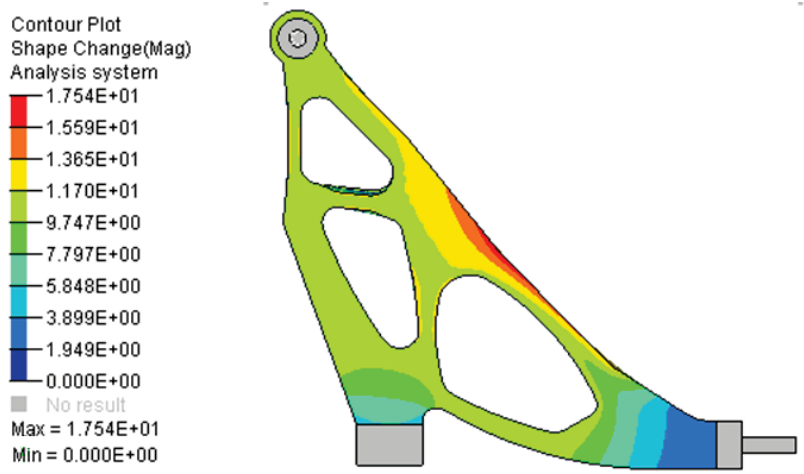

Figure 16 Contour plot of shape Change for different areas of the component (mm)

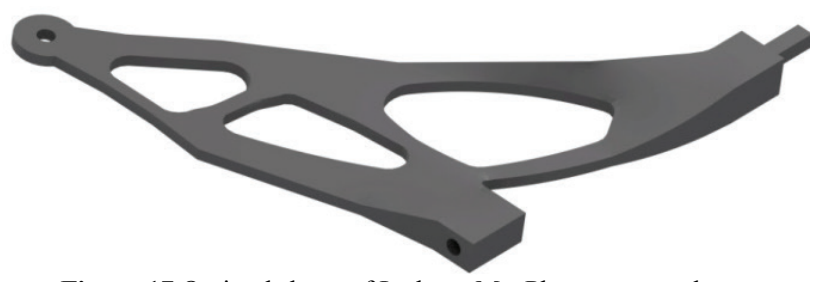

Figure 17 Optimal shape of L-shape MacPherson control arm
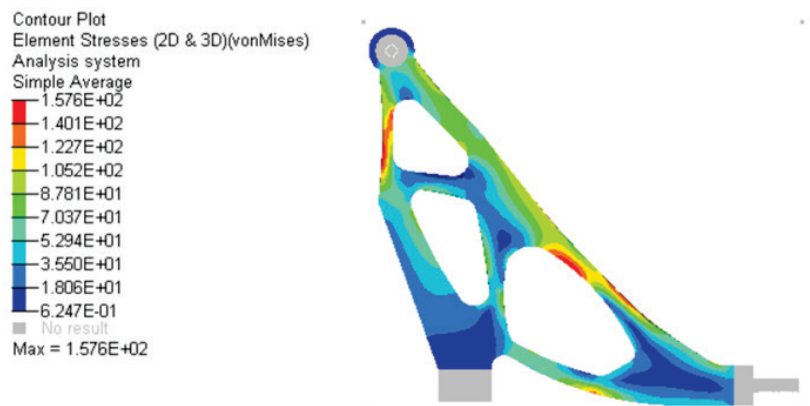

Figure 18 Stress distribution of optimized MacPherson control arm

FEA analysis shows maximum Von Mises stress value of $157,6 \mathrm{MPa}$ on optimized component, which is below the yield limit as shown in Fig. 18. According to Tab. 4 , the safety factor of optimal design is 2,85 which can be calculated as follows:

Safety factor $=\frac{\text { Yield Stress }}{\text { Maximum Stress }}=2,85$
In addition, the minimum fatigue life has been calculated 1,33 million cycles which is within acceptable limit, according to American society for testing and materials [1], as shown in Fig. 19.
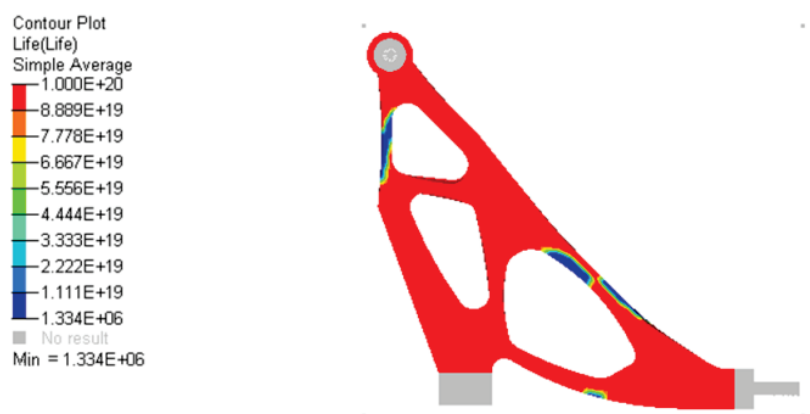

Figure 19 Fatigue life distribution of optimized MacPherson control arm

Table 4 Comparing results of optimization steps

\begin{tabular}{|l|c|c|c|}
\hline & $\begin{array}{c}\text { Mass } \\
(\mathrm{kg})\end{array}$ & $\begin{array}{c}\text { Minimum } \\
\text { Fatigue Life } \\
\left(10^{6} \text { cycles }\right)\end{array}$ & $\begin{array}{c}\text { Maximum Von } \\
\text { Mises stress } \\
(\mathrm{MPa})\end{array}$ \\
\hline Primary model & 3,6 & 1,9 & 70,6 \\
\hline Optimal topology & 1,8 & - & - \\
\hline Modified CAD & 2,2 & 1,46 & 70,8 \\
\hline Final model & 0,75 & 1,33 & 157,6 \\
\hline
\end{tabular}

\section{Conclusion}

In the paper, the complex two-stage optimization methodology with fatigue constraints was presented. As observed in the numerical example of the structure subjected to high-cycle fatigue loads, the proposed approach allowed one to effectively reduce the mass of the structure, maintaining its fatigue durability on an established level taken from the real object. The second stage of topology optimization improved the result by removing the excessive material which, clearly, could not be removed by the first method. What is interesting, the topology optimization method gives very good results for already optimized objects. After analysis of the new optimized design, results revealed that:

- The presented methodology reduces cycle time for design of MacPherson arm.

- The mass reduction for the control arm was found to be $25 \%$ compared to the currently used model, with desired fatigue life and strength.

- These two consecutive optimization processes which can avoid the dependency on personal experience, improve the accuracy of the optimal results, meanwhile decrease the time in product design.

- OptiStruct optimization with fatigue process manager is a powerful tool to achieve lighter and more reliable conceptions with significant reduction in cycle time.

This result is satisfactory considering shape optimization with limited design space given and no change in material properties. More reduction, though may not be much, is expected to be achieved if there is more design space through redesigning of the whole assembly. For further research, the experimental works under controlled laboratory conditions should be done to determine the validation of the result from the software analysis. Aluminium alloy 7075-T6 should be considered 
as the suitable material for the fabrication of the suspension arm. The approach used in this paper can be applied to other vehicle components to reduce vehicle weight; therefore, there is a potential to contribute towards environment sustainability by better conserving world's metal resources and reducing carbon emission through improved overall vehicle fuel efficiency.

\section{References}

[1] American Society for Testing and Materials. Standard Practice for Strain Controlled Fatigue Testing. // Annual book of ASTM standards. 3(2012), pp. 53- 59.

[2] Bendsoe, M. P.; Sigmund, O. Topology Optimization Theory, Methods and Application. Springer-Verlag, Berlin, 2003.

[3] Bendsoe, M. P.; Kikuchi, N. Generating Optimal Topologies in Structural Design Using a Homogenization Method. // Comput Method Appl M. 71, 1(1988), pp. 197224. DOI: $10.1016 / 0045-7825(88) 90086-2$

[4] Chiandussi, G.; Gaviglio, I. Topology Optimization of an Automotive Component without Final Volume Constraint Specification. // Adv Eng Softw. 35, 11(2004), pp. 609-617. DOI: 10.1016/j.advengsoft.2003.07.002

[5] Das, R.; Jones, R. Topology Optimization of a Bulkhead Component Used in Aircrafts Using an Evolutionary Algorithm. // 11th International Conference on the Mechanical Behavior of Materials, 2011, pp. 2867-2872.

[6] Doundkar, V. Topology Optimization for Engine Mount Arm with Fatigue. Research report (2011), Mumbai, Force Motor Company.

[7] Farrahi, G. H.; Khalaj, A. Estimation of Fatigue Damage Caused by Actual Roads and Maneuvers on Proving Ground. // JAMME. 14, 1(2006), pp. 90- 97.

[8] Lampman, S. R.; DiMatteo, N. D. ASM Handbook: Fatigue and fracture. ASM International, 1996, $1057 \mathrm{p}$.

[9] Hippoliti, R. FEM Method for Design and Optimization of Connecting Rods for Small Two Stroke Engines. // Small Engine Technology Conf. 1993, pp. 217-231.

[10] Hullender, D. A. Generation of a random time series with a specified spectral density function. University of Texas at Arlington, submitted through ASME for JACC, 1979.

[11] Ishida, S.; Hori, Y.; Kinoshita, T.; Iwamoto, T. Development of Technique to Measure Stress on Connecting Rod and Topology Optimizations. SAE 951797, 1995, pp. 1851-1856.

[12] Inamdar, K. V. Vehicle Suspension Optimization for Stochastic Inputs. M.S. dissertation (2011), University of Texas, Arlington, USA.

[13] Kojima, Y. Mechanical CAE in Automotive Design. // R \& D review of Toyota CRLD. 35, 4(2000).

[14] Krishnapillai, K.; Jones, R. Fatigue Based 3D Structural Design Optimization Implementing Genetic Algorithms and Utilizing the Generalized Frost-Dugdale Crack Growth. // Proceeding of the 9th WSEAS Int. Conference on Mathematical and Computational Methods in Science and Engineering/ Trinidad and Tobago, 2007, pp. 490-497.

[15] Makino, T.; Koga, T. Topography \& Shape Optimization. // Mitsubishi Industries Ltd. technical review. 39, 1(2002).

[16] Rainer M. P. Significant Weight Reduction by Using Topology Optimization in Volkswagen Design Development. // Optimization Technology Conference / Michigan, 2005, pp. 27-28.

[17] Schramm, U.; Thomas, H.; Zhou, M. Manufacturing Considerations and Structural Optimization for Automotive Components. Society of Automotive Engineers, SAE 200201-1242, 2002.

[18] Sharafi, P.; Teh, L.; Hadi, M. Shape Optimization of Thinwalled Steel Sections Using Graph Theory and ACO
Algorithm. // JCSR. 101, 10(2014), pp. 331-341. DOI: 10.1016/j.jcsr.2014.05.026

[19] Song, X. G.; Jung, J. H. Metamodel-based Optimization of a Control Arm Considering Strength and Durability Performance. // Omput Math Appl. 60, 1(2010), pp. 976980. DOI: 10.1016/j.camwa.2010.03.019

[20] Wan Muhamad, W. M. An Optimization Analysis on an Automotive Component with Fatigue Constraint Using HyperWorks Software for Environmental Sustainability. // WASET. 68, 1(2012), pp. 243- 248.

[21] Wong, J. Y. Theory of Ground Vehicle. 4th ed. Wiley, Hoboken, 2001.

[22] Zurofi, M. Manufacturing Process Effects on Fatigue Design and Optimization of Automotive Components- an Analytical and Experimental Study. PhD dissertation (2004), The University of Toledo, USA.

[23] Zhao, L. H.; Zheng, S.; Feng, J. Dynamics Structure Optimization of Lower Control Arm Based on ESL. // Res J Appl Sci Eng Tech. 4, 22(2012), pp. 4871-4878.

[24] Zhu, B.; Zhang, X.; Fatikow, S. Structural Topology and Shape Optimization Using a Level Set Method with Distance-suppression Scheme. // CMAME. 283, 1(2015), pp. 1214-1239. DOI: 10.1016/j.cma.2014.08.017

\section{Authors' addresses}

Javad Marzbanrad, PhD, Associate Professor (Corresponding author)

School of Automotive Engineering,

Iran University of Science and Technology, Narmak, 16846-13114, Tehran, Iran

E-mail: marzban@iust.ac.ir

\section{Abolfazl Hoseinpour, MSc}

School of Automotive Engineering,

Iran University of Science and Technology,

Narmak, 16846-13114, Tehran, Iran

E-mail: miladhoseinpour@gmail.com 